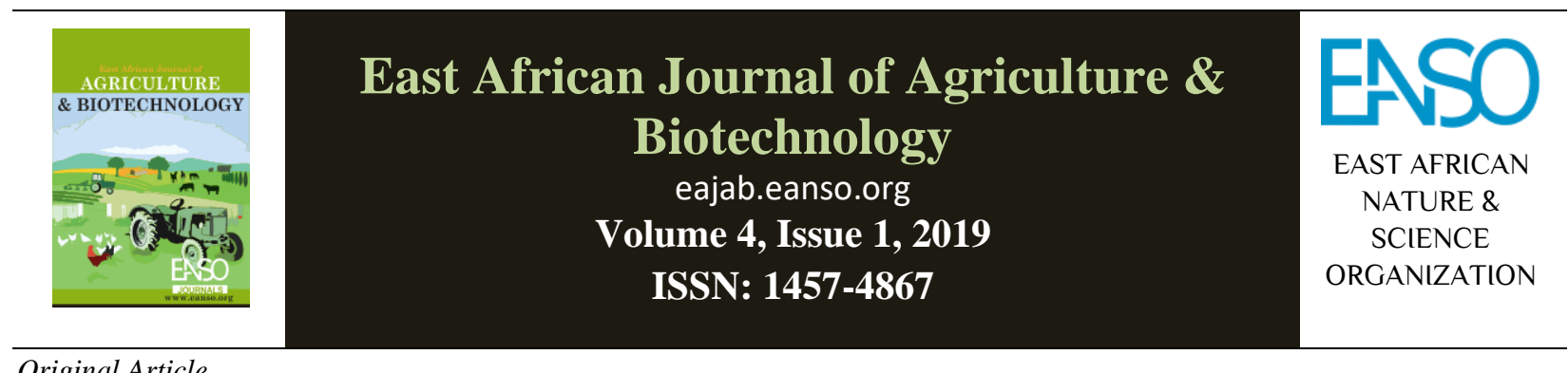

Original Article

\title{
SEROSURVEILLANCE FOR AVIAN INFLUENZA IN LOCAL CHICKENS IN HOUSEHOLDS AND LIVE BIRD MARKETS IN ENUGU STATE, NIGERIA
}

\section{Okoli Solomon Chieloka}

African Field Epidemiology Network, Federal Ministry of Agriculture and Rural Development, Nigeria, okoli28@gmail.com.

DOI: https://doi.org/10.37284/eajab.1.1.52

\section{Article history:}

Received: 30 Oct 2019

Accepted: 05 Nov 2019

Published: 13 Nov 2019

Keywords:

Live Bird Market

(LBM),

Avian influenza

(AI),

Highly Pathogenic

Avian Influenza

(HPAI),

Biosecurity,

Enugu State,

Nigeria

\section{ABSTRACT}

Enugu State, Nigeria has previously reported an outbreak of avian influenza in three local governments namely Igoetiti, Nkanu west and Udi following the resurgence of avian influenza in 2015. Traceback investigation on affected farms showed a direct link of confirmed outbreaks to the presence of apparently healthy asymptomatic local chicken roaming freely as resident local chicken within intensive farms. However, there was a paucity of data to support this hypothesis. Two hundred (200) serum samples were obtained from apparently healthy local chicken at the live bird market (Ibagwa Nkwo Nsukka) and purposively selected households within Enugu state. Serology for Avian influenza-specific antibodies was conducted using the Agar Gel immunodiffusion test. Semi-structured questionnaires were used to access the level of awareness of respondents to avian influenza (AI), management practices that may be associated with suspected cases of avian influenza and accessibility to veterinary care within the study area. The level of awareness for avian influenza was low, 31(48.4\%), there was no association between gender, education of respondents and level of awareness about avian influenza within the study area, $\left(\mathrm{P}=0.348, \chi^{2}=1.035 ; \mathrm{df}=2\right),\left(\mathrm{P}=0.329, \chi^{2}=2.225 ; \mathrm{df}=2\right)$. $53(82.8 \%)$ of the respondents reported to be aware of the availability of veterinary care; however, $21(39.6 \%)$ reported that limited fund was militating factor in accessing the services. Risk factors to avian influenza zoonosis included consumption of dead poultry "Morta" (22, 34.4\%); open disposal of carcasses $(23,35.9 \%)$ and mixing of local chickens with known reservoirs of avian influenza where ducks $(76,17.2 \%)$ and pigeons $(119,26.9 \%)$ were very common. Serological findings showed that all 200 samples (serum) were negative for avian influenza antibodies, premised on this finding, it was concluded that local chickens may not serve as reservoirs of avian influenza in the study area within the time frame. 


\section{INTRODUCTION}

Highly pathogenic avian influenza (H5N1) was first reported in Nigeria in 2006 where it persisted until 2008, resulting in one AI case in a woman in Lagos, (Monne et al., 2007), 25 across 97 local government areas were affected (Fusaro et al., 2009). About 1,525 suspected cases of HPAI were reported during this period; however, Nigeria was declared free of avian influenza in 2013 (Nyager, 2013). A year after this declaration, Coker et al. (2014) reported a circulating level of low pathogenic avian influenza in duck at the Shasha live bird market in Ibadan southwest Nigeria. In 2015, a resurgence of highly pathogenic avian influenza was reported following increased mortality at a live bird market in Lagos and backyard poultry farms in Kano state (Monne et al., 2015). The possible emergence of a novel influenza strain with no prior human or animal immunity has remained a talking point within the scientific circle. The isolation of influenza A subtype H5N8, in Kano State (OIE, 2016), and Oyo State (OIE, 2017) has brought to the fore the urgent need for a comprehensive review of the current control policies of the Federal Ministry of Agriculture towards stamping out of avian influenza in Nigeria and ensuring food safety.

Enugu state-reported five suspected cases of HPAI and H5N1 between 2015-2018, three of these cases were confirmed to be highly pathogenic avian influenza. As in the first quarter of 2018, a sporadic outbreak of avian influenza was still being reported in certain states of the federation with the detection of H5N8 in Kano state in northwest Nigeria (OIE, 2016). As of the first quarter of 2018, 26 states had reported an outbreak of HPAI with over $\$ 700$ million paid as compensation to affected farmers and another 1.6 billion as outstanding claims, (FDLPCS, 2017). This research work aimed to identify remote and immediate factors responsible for the outbreak of avian influenza in Nigeria and provide data for policy development towards findings a long-lasting solution to the outbreaks and spread of Avian influenza within Nigeria thus ensuring and enhancing public health and food safety.

Figure 1: Cases of Avian Influenza Between 2015- $2^{\text {nd }}$ February 2018

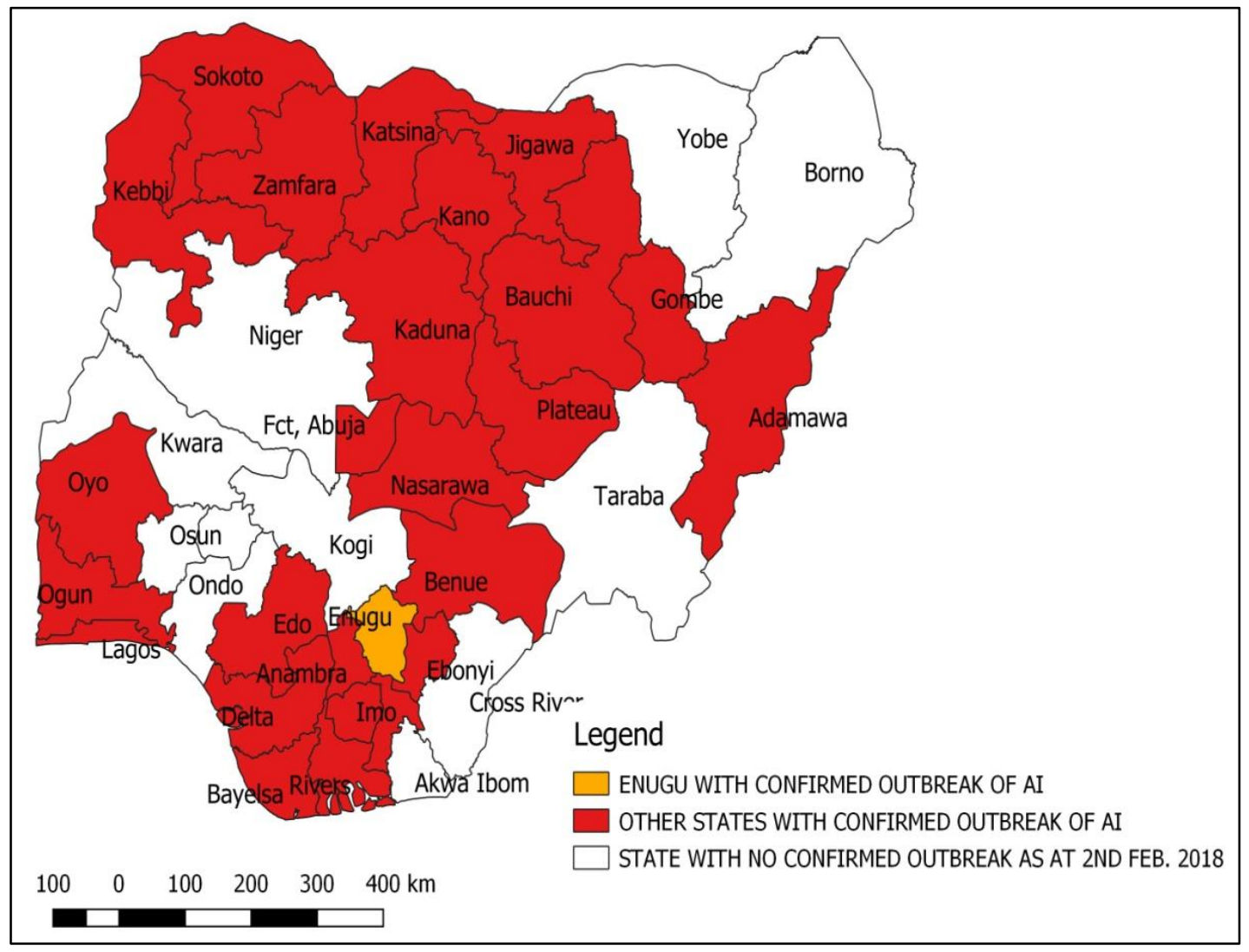




\section{MATERIALS AND METHODS}

\section{Study Area}

Enugu State was created in 1991 from the old Anambra State; it is bordered by Abia and Imo State to the south, Ebonyi State to the East, Benue State to the North East, Kogi state to the northwest and Anambra State to the west. It lies between latitude $6^{\circ} 30 \mathrm{~N}$ and longitude $7^{\circ} 30 \mathrm{E}$ with an approximate land mass of $7.161 \mathrm{Km}^{2}$ (2,765 sq. mile). It is located in the tropical savannah zone of Nigeria. It has a population of $3,267,837$ people
(NPC, 2006). The total number of poultry in Nigeria is estimated to be 145 million birds (NASS, 2015). Enugu state has 17 local government areas (LGAs) subdivided into 6 agricultural zones namely Agwu, Agbani, Enugu, Nsukka, Enugu Ezike, and Udi. Crop and livestock farming is the major occupation of the people (Chah et al., 2014). There are 6 slaughterhouses in Enugu at Enugu ezike, 9th mile, Nenwe, Adani, Ogbette, and Nsukka; one pig market at Orie Oba; artisan poultry market and Ugwu Oba live bird market. There are two control posts at Obollo Afor interstate control post and Ugwu Oba control post.

Figure 2: Outbreak of Avian Influenza Between (2015-2018) by LGAs in Enugu State

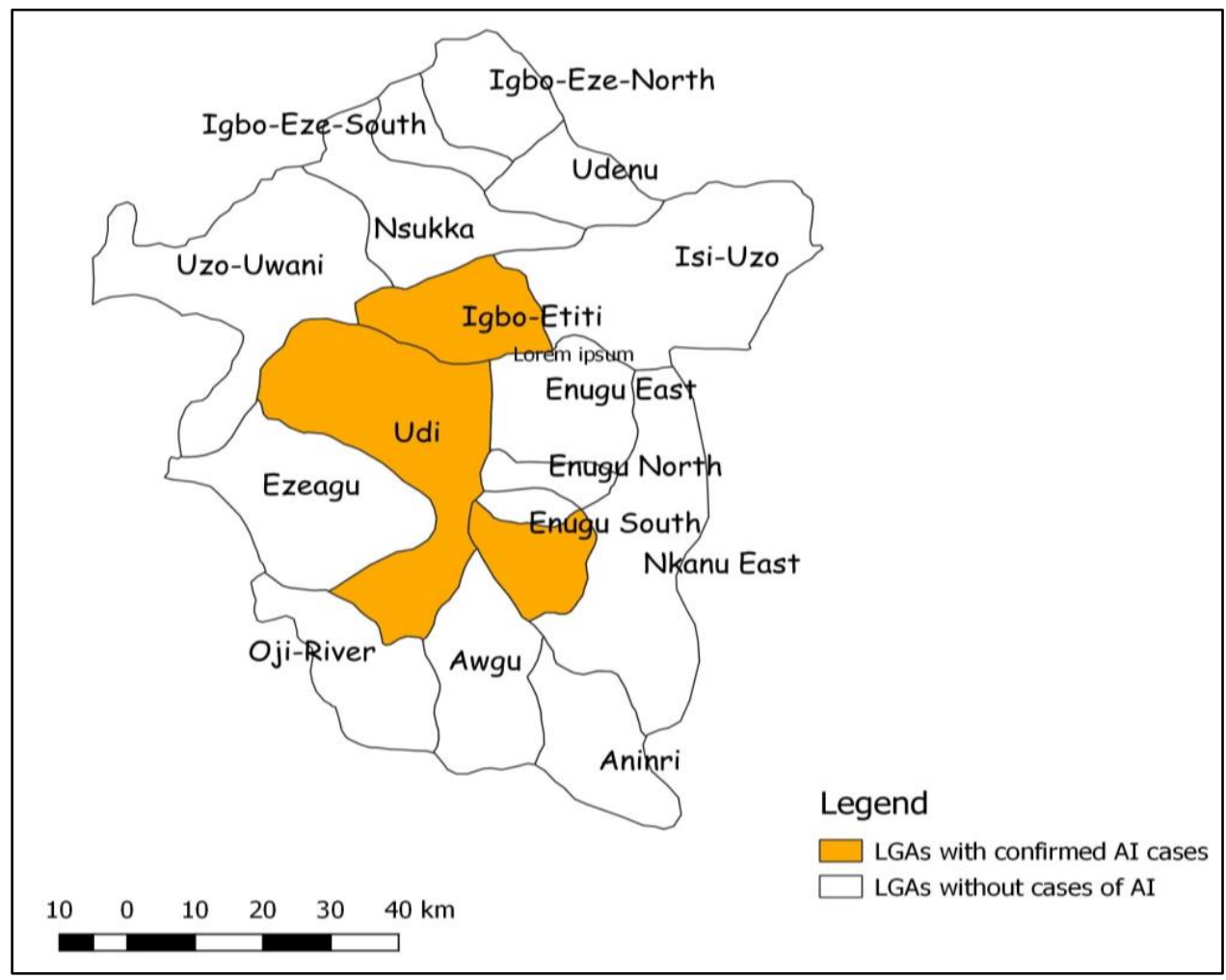

\section{Agar gel Immunodiffusion Test and Procedure}

The $100 \mathrm{ml}$ Agar used was prepared where $8 \mathrm{~g}$ of $\mathrm{NaCl}$ and 1g Agarose was weighed the salt mixture is then poured into a sterile bottle $(500 \mathrm{ml})$ and later $100 \mathrm{ml}$ of PBS ( $\mathrm{pH}$ adjusted to 7.2) was added. The heat was supplied to the mixture until it completely dissolves. Dispense $15 \mathrm{ml}$ of the melted Agar into $100 \times 15 \mathrm{~mm}$ sterile Petri dishes placed on level surface open until the Agar is set. The plate was incubated and stored at $+4{ }^{\circ} \mathrm{C}$ until use

\section{Surveillance Team}

The team members include: (a) the Researcher as the facilitator (b) AI Desk Officer for LGA in Enugu (d) one additional animal health worker in the locality. These participants were retrained on $\mathrm{PE}$ and assigned roles.

\section{Study Design}

A cross-sectional survey design was adopted for the study interviews were conducted using a semi- 
structured questionnaire was used to obtain information from local poultry keepers. Parameters accessed by a questionnaire includes poultry management system, level of awareness of respondents to avian influenza, clinical signs associated with suspected cases of AI, method of disposal of carcasses, source of feed and availability of veterinary care amongst others. Similarly, a serological test to determine the prevalence of avian influenza in local chicken was conducted using the Agar gel immunodiffusion test.

The study population included local chickens in households, local chicken at the live bird markets and surveillance point agents within the study area. The sample size was determined using a mean prevalence of $4.2 \%$, (Ameji et al., 2016), 13\% (Coker et al, 2014) and 2.9\%, (Gugong et al., 2012); by (Thrusfield, 1997). The following formula was used: $\mathrm{n}=\frac{\mathrm{z}^{2} \mathrm{pq}}{\mathrm{d}^{2}}$ where $q=1-\mathrm{p}, n=$ sample size $p=$ anticipated prevalence (6.7) $d=$ desired precision (0.05) and $z=$ appropriate value from the normal for the desired confidence (1.96). A sample size of 96 local chicken was determined since samples are to be collected at two main units LBM and household, it follows that 96+96 = 192

\section{Sampling Technique}

A systematic random sampling technique of 1:3 was used to select ten cages containing local chicken at the live bird markets where a random sample of 10 chickens was made from each cage to make a total of 100 birds. Purposive sampling technique was used to select households keeping local chickens and samples were collected from chicken selected at random.

\section{Blood Sample Collection}

The brachial vein was sterilized using $70 \%$ alcohol; 2-3 $\mathrm{ml}$ of blood was collected using a $5 \mathrm{ml}$ syringe with a 21-gauge needle. A blood sample was dispensed in a sterile test tube, slanted for 2 hours to allow blood clot and separation of sera subsequently sera was decanted into an Eppendorf tube, which was stored in a Coleman pack and transported to the laboratory.

\section{Procedure for Agar gel immunodiffusion test}

$1 \%(\mathrm{w} / \mathrm{v})$ Agarose and $8 \%(\mathrm{w} / \mathrm{v}) \mathrm{NaCl}$ in $0.01 \mathrm{M}$ phosphate buffer solution $\mathrm{PH} 7.2$ was dissolved in $100 \mathrm{ml}$ distilled water, the solution was stirred gently and incubated in a humidified chamber for 10 minutes. Subsequently, $15 \mathrm{ml}$ of the solution was dispensed into $9 \mathrm{~cm}$ diameter Petri dishes and allow cooling at room temperature. Using a template cutter, wells of approximately $5 \mathrm{~mm}$ in diameter were cut into the gel on the petri dish as shown below (OIE, 2014).

Figure 3: Representation of experimental landmark of Agar gel immunodiffusion medium showing positive and negative test after the result
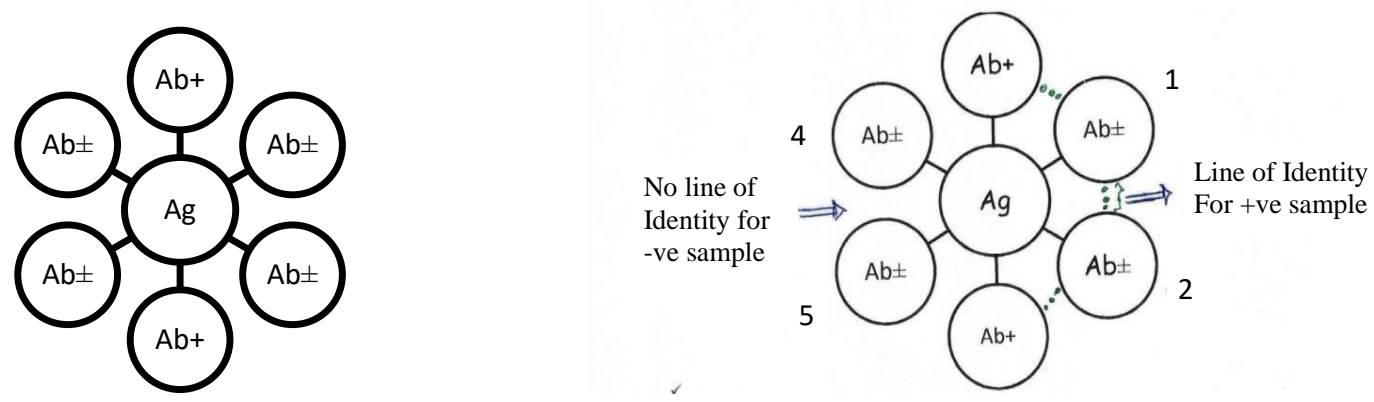

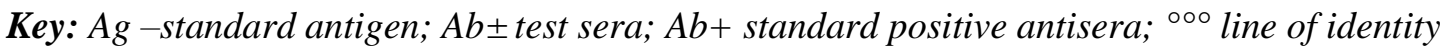


The pattern of well is such that about $50 \mu \mathrm{m}$ of each test serum samples were dispensed into the peripheral wells $(\mathrm{Ab} \pm)$ and the known avian influenza antigen is dispensed into the central well $(\mathrm{Ag}+)$, all corresponding to the meniscus. The sample was incubated for 24 hours and viewed in a dark background using oblique light. Regions of precipitation between the specific known avian influenza antigen and antibodies (Serum samples) is an indication of the positive test result and vice versa. Inactivated avian influenza (H5) antigen and antiserum were (strain A/duck/Potsdam/1402/86) obtained from the Avian influenza reference Lab. Padova Italy and used as the standard avian influenza antigen and antibodies respectively, Agar gel immunodiffusion test was conducted as described by (OIE, 2014).

\section{RESULTS}

\section{Level of Awareness, Knowledge of Clinical Signs and Management Practice}

The level of awareness of highly pathogenic avian influenza (HPAI) was low $(31,48.4 \%), 33(51.6 \%)$ had no knowledge of avian influenza. 6(51.6\%) of those who were knowledgeable about AI identified at least three clinical/PM signs that could be associated with suspected cases of HPAI. These were purple discoloration of the wattle, comb, bleeding ovaries seen at slaughter unusually high mortality. $15(48.4 \%)$ of the knowledgeable respondents could identify at least two of the clinical signs that are associated with avian influenza namely swollen head and pin point haemorrhages on the shanks.

On availability of veterinary care, $53(82.8 \%)$ of the respondents posited that veterinary care was available within the study area, where out of these, $32(60.4 \%)$ reported that veterinary care was affordable while 21 (39.6\%) claimed they were beyond their reach. Considering sex demography of the respondents (Table 1), female respondents accounted for $36(62.5 \%)$ and male respondents, 28 $(37.5 \%)$. There is no association between gender and level of awareness of avian influenza $(\mathrm{P}=$ $0.348 ; \mathrm{X}^{2}=1.035 \mathrm{df}=2$ ). However, male respondents were more informed about avian influenza $12(52.17 \%)$ than females $11(47.83 \%)$ respondents.
Table 1: Distributions showing genders of respondent and awareness about AI

\begin{tabular}{|c|c|c|c|}
\hline Gender & $\begin{array}{l}\text { Awareness } \\
\text { about AI }\end{array}$ & $\begin{array}{l}\text { Not } \\
\text { aware of } \\
\text { AI }\end{array}$ & Total \\
\hline Male & 12 & 16 & 28 \\
\hline Female & 11 & 25 & 36 \\
\hline Total & 23 & 41 & 64 \\
\hline
\end{tabular}

Table 2 showed that there was no significant association $(P=0.329)$ between the educational status of respondent and their level of awareness of avian influenza, although level of awareness is higher in respondents with secondary education 14 $(60.87 \%)$, tertiary education, $8(34.78 \%)$ and primary education $(4.34 \%)$ respectively.

Table 2: Distribution of educational levels and awareness about $\mathrm{AI}$

\begin{tabular}{llll}
\hline $\begin{array}{l}\text { Educational } \\
\text { Status }\end{array}$ & $\begin{array}{l}\text { Aware } \\
\text { About } \\
\text { AI }\end{array}$ & $\begin{array}{l}\text { Not } \\
\text { Aware } \\
\text { About AI }\end{array}$ & Total \\
\hline Secondary & 14. & 21 & 35 \\
Primary & 8 & 6 & 14 \\
Tertiary & 9 & 6 & 15 \\
Total & $\mathbf{3 1}$ & $\mathbf{3 3}$ & $\mathbf{6 4}$ \\
\hline
\end{tabular}

$P=0.329\left(\chi^{2}=2.225 ; d f=2\right)$

Furthermore, Table showed that farmers $12(53.33 \%)$ were more informed than civil servants $7(23.33 \%)$ and students $5(10 \%)$, however, there is no association $(\mathrm{P}=0.954)$ between the occupation of the respondents and their level of awareness.

Table 3: Distribution showing occupation of respondents and awareness of $\mathrm{AI}$

\begin{tabular}{|c|c|c|c|}
\hline $\begin{array}{l}\text { Occupati } \\
\text { on }\end{array}$ & $\begin{array}{l}\text { Awareness } \\
\text { of AI }\end{array}$ & $\begin{array}{l}\text { Not aware } \\
\text { of AI }\end{array}$ & $\begin{array}{l}\text { Tot } \\
\text { al }\end{array}$ \\
\hline Farmer & 12 & 15 & 27 \\
\hline $\begin{array}{l}\text { Civil } \\
\text { Servant }\end{array}$ & 7 & 8 & 15 \\
\hline Student & 5 & 6 & 11 \\
\hline $\begin{array}{l}\text { Not } \\
\text { Indicated }\end{array}$ & 6 & 5 & 11 \\
\hline
\end{tabular}




\section{Result of Serology for Avian Influenza Antibodies}

There was no precipitation band formed in all 200 serum samples screened for avian influenza antibodies in local chicken using Agar gel immunodiffusion techniques, Figure 4.

Figure 4: Agar gel immunodiffusion test result with no region of precipitation (Negative text)

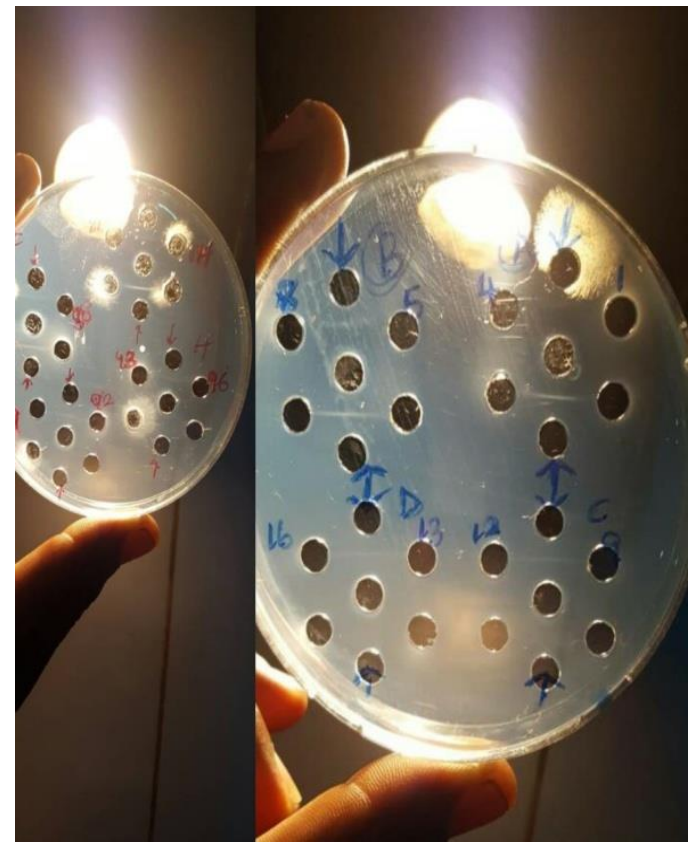

Agar gel immunodiffusion test.

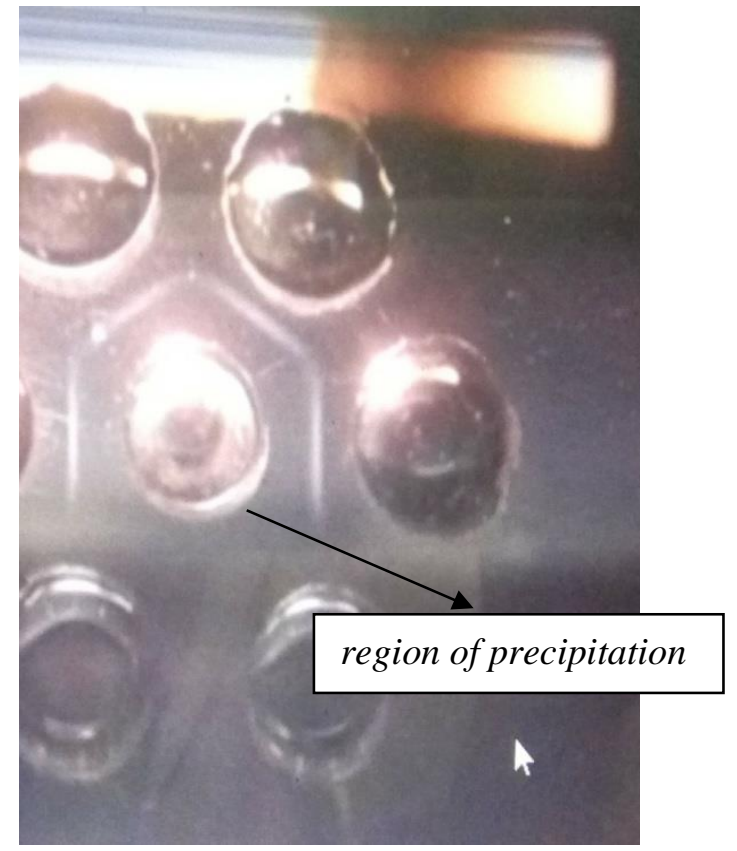

Standard Control

\section{Poultry Production with Associated Risk at the Live-bird Markets and Households}

In Table 4, 41(64.06\%) of the respondents supplemented their feeds with feed waste from the live bird market, 19(29.69\%) of the respondent feed their poultry from waste from commercial farms while $4(6.26 \%)$ purchased commercial feed for their poultry stock. The findings of the study further showed that Newcastle disease $(5.3 \pm 0.96)$, fowl pox $(2.3 \pm 0.96)$, Coccidiosis $(4.8 \pm 0.96)$, and flea infestation (1.8 \pm 0.96$)$, were the common diseases affecting poultry birds during the study period (see Table 4).

Table 4: Poultry diseases reported at Ibagwa Nkwo LBM between March-April, 2017

\begin{tabular}{lllll}
\hline Local bird sellers & $\begin{array}{l}\text { Fowl Pox } \\
\text { (Kitipa) }\end{array}$ & $\begin{array}{l}\text { Newcastle } \\
\text { (Agbago olu) }\end{array}$ & $\begin{array}{l}\text { Coccidiosis (Ôria } \\
\text { nsi mmiri) }\end{array}$ & $\begin{array}{l}\text { Flea infestation } \\
\text { (Akpiri) }\end{array}$ \\
\hline I & 2 & 6 & 4 & 1 \\
II & 1 & 4 & 5 & 2 \\
III & 3 & 6 & 5 & 3 \\
IV & 3 & 5 & 6 & 1 \\
Mean Score \pm SD & $2.3 \pm 0.96$ & $5.3 \pm 0.96$ & $4.8 \pm 0.96$ & $1.8 \pm 0.96$ \\
\hline
\end{tabular}


East African Journal of Agriculture and Biotechnology, 4(1), 2019

Table 5 described the level of mixing/rearing of poultry stock with other animals at Ibagwa Nkwo live bird market where a total of 443 poultry kept comprising 248(55.6\%) local chicken, 119 (26.9\%) pigeons, and 76(21.7\%) ducks.

Table 5: Stocking of different poultry species and swine at Ibagwa Nkwo LBM, Nsukka

\begin{tabular}{llllll}
\hline Categories & Local Chicken & Pigeon & Duck & Swine & Coordinates \\
\hline A & 20 & 8 & 12 & 6 & N06 $^{\circ} .91462, \mathrm{E} 008.39664$. \\
B & 31 & 14 & 6 & - & N06 $^{\circ} .96432, \mathrm{E} 008.49364$ \\
C & 34 & 16 & 14 & - & N06 $^{\circ} .86231, \mathrm{E} 008.59564$ \\
D & 15 & 6 & 6 & 13 & $\mathrm{~N}^{\circ} .56531, \mathrm{E} 008.56561$ \\
$\mathbf{E}$ & 26 & - & - & 4 & $\mathrm{~N}^{\circ} 06^{\circ} .55531, \mathrm{E} 008.66511$ \\
$\mathbf{F}$ & 21 & - & 9 & 9 & $\mathrm{~N}^{\circ} .45571, \mathrm{E} 008.67513$ \\
$\mathbf{G}$ & 14 & 15 & 10 & 12 & $\mathrm{~N}^{\circ} 06^{\circ} .85571, \mathrm{E} 008.77513$ \\
$\mathbf{H}$ & 34 & 9 & - & - & $\mathrm{N}^{\circ} .95571, \mathrm{E} 008.77815$ \\
$\mathbf{1}$ & 32 & 21 & - & - & $\mathrm{N}^{\circ} 06^{\circ} .75971, \mathrm{E} 008.47835$ \\
J & 21 & 15 & 19 & 8 & $\mathrm{~N}^{\circ} .65974, \mathrm{E} 008.43885$ \\
Total & $\mathbf{2 4 8}$ & $\mathbf{1 1 9}$ & $\mathbf{7 6}$ & $\mathbf{5 2}$ & \\
\hline
\end{tabular}

Table 6: Distribution of methods of management of sick poultry/poultry carcasses at the LBM and households

\begin{tabular}{lc}
\hline Management & Number and \% of respondent \\
\hline Veterinary intervention & $11(17.2)$ \\
Sell off sick birds & $42(65.6)$ \\
Slaughter and consume sick or dead poultry & $11(17.2)$ \\
\hline
\end{tabular}

\section{DISCUSSION}

There was general apathy amongst the poultry stakeholders to participate in the study sighting previous visits by a representative of the government with no justifiable outcome. However, the application of persuasive technique and confidence building encouraged some poultry farmers to participate in the study.

Respondents demonstrated a good degree of understanding of clinical signs associated with common local diseases, though the level of awareness of avian influenza was low 31(48.4\%), in contrast to $87 \%$ reported by Durosilorun (2009). Veterinary care was available, 53 (82.8\%), of these population, 21 (39.6\%) reported that the high cost of veterinary care was a militating factor in accessing veterinary services. This may have contributed to the rising practices of ethno veterinary practice within the study area which is in tandem with findings by Anzaku, (2013). This was in sharp contrast to (Ekue et al., 2002) who concluded that the increasing practice of ethno veterinary practice was in direct response to inadequate extension services and low cost of ethno veterinary materials.

Considering management practices with high risk of avian influenza outbreak within the study area, $11(17.2 \%)$ of the respondent slaughter and consume sick or dead chicken "(Morta)" $42(65.6 \%)$ sell off their moribund poultry to small scale eateries and homes while 11(17.2\%) engage the services of veterinary practitioners in management of their flocks. The rationale behind this behaviour is chiefly due to economic reasons and the attendant lack of information on the public health implication of consumption of sick or dead poultry, as such individuals who consume such 
poultry are continuously at risk of avian influenza zoonosis.

Since 2003, the World Health Organization has reported 387 confirmed human cases of HPAIV infection caused by the H5N1 virus. 245 (63\%) persons involved in these confirmed cases died as a result of these diseases (WHO, 2008). Furthermore, developing economies may be at the receiving end of this pandemic (Mckibbon and Sidorenko, 2006), more so the poultry value chain in Nigeria remain poorly regulated, consumption of dead poultry, mixing of different poultry flock may enhance avian influenza viruses to be potentially better adapted to human (WHO, 2005). Considering the gender of the respondents, $28(37.5 \%)$ and 36 $(62.5 \%)$ were male and female, respectively. Male in the eastern part of Nigeria is mostly engaged in import of poultry equipment while female engage in small scale poultry ventures for economic reasons due to the ease of handling poultry as compared to other livestock. Pagani et al. (2008), in a similar study, it was reported that in the southwest of Nigeria the stakeholders of the poultry value chain were either male or female which is a sharp contrast to practices in Northern Nigeria, where males play a dominant role in the poultry subsector largely due to religious inclination. The family 'Anatidae' (Duck, Water birds) has for long been known to play a major role in the transmission of avian influenza viruses between migratory birds and domestic chicken (Coker et al., 2014). Consequently, mixing of these species of poultry with local poultry chicken at a different level of the poultry value chains may provide the needed milieu for adaptation, the emergence of reassortant strains and the outbreak of avian influenza.

Free-range poultry is at a higher risk of coming in contact and roasting with wild birds in the absence of any form of housing, undue exposure to weather may aggravate disease outbreak in reservoir poultry. The demography of occupation of the respondents shows that $63.6(53 \%)$ were full-time farmers, $27.6(23 \%)$ were civil servants, and 12 $(10 \%)$ were students at different levels of the institution. Poultry farming provides a source of income to supplement the earnings of students and civil servants who are stakeholders, it may also serve as an indicator that the current drive of the Federal Government of Nigeria, to make the agricultural venture profitable may be yielding dividend.

The source, quality, and quantity of poultry feeds are integral to good animal husbandry; it improves resistance to infection (Mavale, 2001). 41(64.1\%) of the respondents supplement their feeds with food waste from the live bird market, 19 (29.7\%) with waste from commercial farms and 4 (6.3\%) give commercial feed. It's instructive to note that feed waste obtained from the live bird markets or commercial poultry farms may harbour infectious agents and provides a suitable medium for the growth of viral agents. Similarly, faecal contaminated feeds from reservoir poultry may lead to a disease outbreak in the naïve poultry population.

The poor economic status of poultry local chicken sellers, the paucity of information relating to the public health implication of such practices is the bane of effective disease control in the study area. The government can play a leading role in subsidizing the price of feed for peasant farmers, and revitalization of the moribund extension services may go a long way in ensuring food safety. The implications and improper management of poultry carcasses and sick flocks can never be overemphasized, open disposal of dead or sick poultry carcasses makes it possible for wild birds, free-range poultry, and scavenging mammals to feed on them and such birds may become sentinels for spread of new infection and by extension households with scavenging pets are continuously at risk of avian influenza zoonoses. There were no antibodies to influenza A viruses detected in sera of apparently healthy local chicken at the live bird markets and households in Enugu State Nigeria. This was in contrast with findings by Ameji et al., (2016), who reported presence of antibodies to influenza A Viruses, (4.2\%) in backyard and rural poultry chicken in Kogi State Nigeria, El-Yuguda and Baba (2002), reported the presence of antibodies to influenza A viruses in village chicken in Borno state, and (Gugong et al, 2012) demonstrated the presence of influenza A subtype (H5) $(2.9 \%)$ in local chicken in Kaduna state .

Local poultry are rarely vaccinated (Dipeolu et al., 1998), the presence of antibodies to influenza A viruses in serum of bird may be due to natural 
infection (Biswas et al, 2009; Wakawa et al., 2009), exposure of naïve birds to reservoirs / carriers of avian influenza viruses, and prophylactic use of AI vaccines. It is instructive to note that following the resurgence of avian influenza in 2015, the federal government stepped up biosecurity measures across the country especially in states where outbreak has already been reported, the resultant (culling of infected poultry, carrier birds, decontamination of farms and recently compensation of affected farmers) these have played a major role in curbing spread of infection in poultry. This underscores the importance of continuous active disease surveillance, and biosecurity measures towards prevention and control of avian influenza outbreak (De Benedictis et al., 2007), at every level of the poultry value chain. Survey of Ten (10) local chicken sellers who also keep other sentinel species at the live bird market shows 248 (50.1\%) were local chickens $(119,24.4 \%)$, pigeon $(76,15.4 \%)$, and pigs $(52,10.5 \%)$. Rearing of pigeon with local poultry is a risk factor in the epidemiology of avian influenza (Coker et al., 2014). Similarly, Pig has been reported as a potential sentinel for the adaptation of avian influenza viruses which may cause zoonotic disease's (Monne et al., 2007), consequently rearing this species of animals together or in close proximity with local chicken should be discouraged

\section{CONCLUSIONS AND RECOMMENDATIONS}

This study has shown that local chickens may not have served as reservoirs of avian influenza in the study area within the time frame (April-May 2016). Consequently, consumption, rearing of local chickens may not pose any public health risk to the populace within the study period. Similarly, intensive farms where these birds roam free as resident local chicken may not be at risk of infection. The level of awareness of avian influenza within the study area is low (48.4\%). Consumption of dead chicken known as "Morta" in local parlance is very popular amongst the respondents, a risk factor in the epidemiology, and adaptation of avian influenza to the human host. Mixing of different species of birds is very common within the live bird markets and this practice may provide the needed milieu for the emergence of new strains of influenza viruses. There should be sustained active surveillance for avian influenza within Enugu State to compliment laboratory analysis and early detection and confirmation of suspected cases of avian influenza. Furthermore, the Enugu State Government should subsidize the cost of veterinary services with a view to making it accessible to small scale farmers. Reactivation of the comatose extension department at the state and federal offices with a renewed vigour on educating farmers on new approaches in tackling endemic and emerging diseases. Bearing in mind the level of mixing of different species of livestock at the live bird markets continuous active serosurveillance should be conducted with a view to determining possible new sentinels of infection. Rearing or mixing of different poultry birds and potential sentinel animal with local chicken should be discouraged toward stamping out of avian influenza from Nigeria and ensuring food safety.

\section{REFERENCES}

Ameji, O. N., Saidu, L., \& Abdu, P. A. (2016). Sero-Prevalence of Avian Influenza in Poultry in Kogi State, Nigeria. Science, 6(1), 1-6.

Anzaku, S. A, (2013). Participatory Epidemiology and Seroprevalence of Newcastle Diseases in Local Chickens in FCT, Abuja-Nigeria. MSC Thesis. Ahmadu Bello University Zaria, Nigeria.

Biswas, P. K., Barua, H., Uddin, G. M. N., Biswas, D., Ahad, A., \& Debnath, N. C. (2009). Serosurvey of five viruses in chickens on smallholdings in Bangladesh. Preventive veterinary medicine, 88(1), 67-71.

Chah, J., Irohibe, I., \& Itodo, C. (2014). Constraints to Indigenous Chicken Production in Enugu State, Nigeria. International Proceedings of Chemical, Biological and Environmental Engineering (IPCBEE), 76, 12-16. IACSIT Press, Singapore.

Coker, T., Meseko, C., Odaibo, G., \& Olaleye, D. (2014). Circulation of the low pathogenic avian influenza subtype $\mathrm{H} 5 \mathrm{~N} 2$ virus in ducks at a live bird market in Ibadan, Nigeria. Infectious diseases of poverty, 3(1), 38 . 
De Benedictis, P., Beato, M. S., \& Capua, I. (2007). Inactivation of avian influenza viruses by chemical agents and physical conditions: a review. Zoonoses and public health, 54(2), 5168.

Dipeolu, M. A., Keripe, O. M., Gbadamosi, A. J., \& Gbadamosi, A. J. (1998). Chick mortality in indigenous chickens under the free-range system in Abeokuta, Nigeria. Nigeria.Veterinary Journal, 19, 5-11.

Durosinlorin, A. (2008). Avian influenza (H5N2) antibodies in local chicken and awareness level of highly pathogenic avian influenza in Kaduna State (M. Sc Thesis). Ahmadu Bello University Zaria-Nigeria.

Ekue, F. N., Pone, K. D., Mafeni, M. J., Nfi, A. N., \& Njoya, J. (2002). Survey of the traditional poultry production system in the Bamenda area, Cameroon. Characteristics and parameters of family poultry production in Africa, 15-25.

El-Yuguda, A. D., \& Baba, S. S. (2002). Prevalence of selected viral infections in various age groups of village chickens in Borno state, Nigeria. Nigerian Journal of Animal Production, 29(1), 245-250.

FDLPCS. (2017, Aug 29). The federal department of veterinary and pest control services, Avian Influenza daily notification. Federal Department Livestock Pest Control Services (FDLPCS)

Fusaro, A., Joannis, T., Monne, I., Salviato, A., Yakubu, B., Meseko, C., ... \& Cattoli, G. (2009). Introduction into Nigeria of a distinct genotype of avian influenza virus (H5N1). Emerging Infectious Diseases, 15(3), 445.

Gugong, V. T., Ajogi, I., Juniadu, K., Okolocha, E. C., Ngbede, E. O., Hambolu, S. E., \& Maurice, N. A. (2012). Avian influenza (H5 subtype) antibodies in village chickens in four local government areas of Kaduna state, Nigeria. Veterinary World, 5(12).

Mavale, A. P. (2001). Country report: Mozambique. Alders, R., \& Spradbrow, P. B. (eds), SADC planning workshop on Newcastle disease control in village chicken (pp. 20-25). Proceedings of an international workshop. Maputo, Mozambique: Australian Centre for International Agricultural Research (ACIAR).

McKibbin, W. J., \& Sidorenko, A. (2006). Global macroeconomic consequences of pandemic influenza (p. 79). Sydney, Australia: Lowy Institute for International Policy.

Monne, I., Joannis, T. M., Fusaro, A., De Benedictis, P., Lombin, L. H., Ularamu, H., ... $\&$ Capua, I. (2007). Reassortant avian influenza virus (H5N1) in poultry, Nigeria, 2007. Emerging infectious diseases, 14(4), 637.

Monne, I., Meseko, C., Joannis, T., Shittu, I., Ahmed, M., Tassoni, L., ... \& Cattoli, G. (2015). Highly pathogenic avian influenza A (H5N1) virus in poultry, Nigeria, 2015. Emerging infectious diseases, 21(7), 1275.

Monne, I., Ormelli, S., Salviato, A., De Battisti, C., Bettini, F., Salomoni, A., ... \& Cattoli, G. (2008). Development and validation of a onestep real-time PCR assay for simultaneous detection of subtype $\mathrm{H} 5, \mathrm{H} 7$, and $\mathrm{H} 9$ avian influenza viruses. Journal of clinical microbiology, 46(5), 1769-1773.

NASS. (2015). National Agricultural Sample Survey, Censors of livestock in Nigeria source National Bureau of statistics.

NPC. (2006). National population Censors. Available at: http://www.population.gov.ng/index.php/censu ses

Nyager, J. (2013). Self-declaration from Nigeria on its disease-free status from notifiable avian influenza Self-declaration. World Organisation for Animal Health.

OIE. (2014). Chapter 3.3.4: Avian influenza (infection with avian influenza viruses). Manual of Diagnostic Tests and Vaccines for Terrestrial Animals. World Organisation for Animal Health (OIE). 
East African Journal of Agriculture and Biotechnology, 4(1), 2019

OIE. (2016). Update on avian influenza in animals (types $\mathrm{H5}$ and $\mathrm{H7}$ ). Retrieved from World Organisation for Animal Health (OIE) at http://www.OIE.int/animal-health-in-theworld/update-on-avian-influenza/2016/

OIE. (2017). OIE Situation Report for avian influenza. Retrieved from World Organisation for Animal Health (OIE) at http://www.OIE.int/fileadmin/Home/eng/Ani mal_Health_in_the_World/docs/pdf/OIE_AI_ situation_report/OIE_SituationReport_AI_10_ 7August2017.pdf

Pagani, P., Abimiku, Y., \& Emeka-Okolie, W. (2008). Assessment of the Nigerian poultry market chain to improve biosecurity. FAO (Nigeria, Consultative Mission on Poultry) Study, 1-65.

Thrusfield, M. (1997). Surveys. In, Veterinary Epidemiology, $2^{\text {nd }} \mathrm{Ed}$ (pp. 178-198). Blackwell Publishing.

Wakawa, A. M., Abdu, P. A., Umoh, J. U., Lawal, S. I., \& Miko, R. B. (2009). Serological evidence of mixed infections with avian influenza and Newcastle disease in village chickens in Jigawa State, Nigeria. Veterinarski arhiv, 79(2), 151-155.

WHO. (2005). WHO global influenza preparedness plan. The role of $\mathrm{WHO}$ and recommendations for national measures before and during pandemics. Department of Communicable Diseases Surveillance and Response, World Health Organisation. Retrieved from http://www.who.int/iris/handle/10665/68998. 